\title{
Effect of 11 September 2001 terrorist attacks in the USA on suicide in areas surrounding the crash sites
}

Cynthia A. Claassen, Thomas Carmody, Sunita M. Stewart, Robert M. Bossarte, Gregory L. Larkin, Wayne A. Woodward and Madhukar H. Trivedi

\section{Background}

The terrorist attacks in the USA on 11 September 2001 affected suicide rates in two European countries, whereas overall US rates remained stable. The effect on attack site rates, however, has not been studied.

\section{Aims}

To examine post-attack suicide rates in areas surrounding the three airline crash sites.

\section{Method}

Daily mortality rates were modelled using time series techniques. Where rate change was significant, both duration and geographic scope were analysed.

\section{Results}

Around the World Trade Center, post-attack 180-day rates dropped significantly $(t=2.4, P=0.0046)$, whereas comparison condition rates remained stable. No change was observed for Pentagon or Flight 93 crash sites.

\section{Conclusions}

The differential effect by site suggests that proximity may be less important that other event characteristics. Both temporal and geographic aspects of rate fluctuation after sentinel events appear measurable and further analyses may contribute valuable knowledge about how sociological forces affect these rates.

\section{Declaration of interest}

None.
The terrorist attacks of 11 September 2001 (9/11) in the USA remain one of the sentinel global events of the decade, exerting a profound influence on world affairs even 9 years later. Salib was the first to label the drop in British suicide rates occurring during the month of the attacks as a demonstration of Durkheimian social principles. ${ }^{1}$ A century ago, Durkheim observed that temporary shifts in levels of social integration and group cohesion induced by sentinel events could affect suicide rates. ${ }^{2}$ However, the influence of the attacks on these rates by site has been inconsistent. Although rates dropped briefly throughout England and Wales, both fatal and non-fatal rates rose in The Netherlands in the months following $9 / 11 .^{3}$ In North America, a post-attack, 24-month elevation in hospitalised non-fatal attempts was observed in a single-site Michigan study, ${ }^{4}$ whereas the rate of suicide attempts treated in emergency departments across the province of Ontario decreased for 3 days after the attacks. A more complete analysis of post-attack suicide rates in the USA represents an additional contribution to this international discussion. We hypothesised that attack site effects would involve a uniform, temporary decline in rates, and that these effects would diminish progressively with increasing geographic distance from the sites, and with increasing time after 11 September 2001.

\section{Method}

\section{Case identification}

The unit of measure for this study was the daily mortality rate per 100000 people, and the study time frame included rates for the 180 days prior to and the 180 days after 9/11 (15 March 2001 to 10 March 2002). Access to official US mortality data files was granted by the National Center for Health Statistics after agency approval of the protocol. Injury-related mortality case identification utilised the World Health Organization's recommended Injury Classification criteria, ${ }^{5}$ and non-injury event case finding used standardised National Center for Health Statistics definitions. ${ }^{6}$ International Classification of Disease (ICD) codes $^{7}$ used in this study were therefore as follows: suicides (ICD-9: E950-E959; ICD-10: X60-X84, X87.0), deaths of undetermined intent (ICD-9: E980-E989; ICD-10: Y10-Y34, Y87.2, Y89.9), ill-defined cause deaths (ICD-9: CM 780-799.9; ICD-10: R00-R99, excluding R95), pancreatic cancer (ICD-9: CM 157; ICD-10: C25) and Alzheimer's disease (ICD-9: CM 331; ICD-10: G30). The deaths of the 9/11 hijackers are designated in the data-set as terrorism-related suicides (ICD-10: U03), and the deaths of all those killed in the attacks as terrorism-related homicides (ICD-10: U01 or U02), ${ }^{8}$ and all of these deaths were excluded from analyses. The deceased's county of residence, rather than county of death occurrence, was used as the geographic locator for each case under the assumption that place of residence would generally be more reflective of the sociocultural group with which the deceased identified.

\section{Geographic parameters}

Except where primary metropolitan statistical areas included partial county areas, sites were all constructed along county lines. Standardised 'immediate vicinity' areas around the World Trade Center and Pentagon attack sites were defined as the counties within the New York City and the Washington-ArlingtonAlexandria, District of Columbia-Virginia-Maryland-West Virginia (DC-VA-MD-WV) primary metropolitan statistical areas respectively. The Pennsylvania crash site of Flight 93 was in rural Somerset County.

Final 2001 US mortality figures suggested that annual, nationwide rates for 2001 were not significantly influenced by the terrorist attacks ${ }^{9}$ and population-based surveys confirm that post-attack manifestations of psychological distress were 


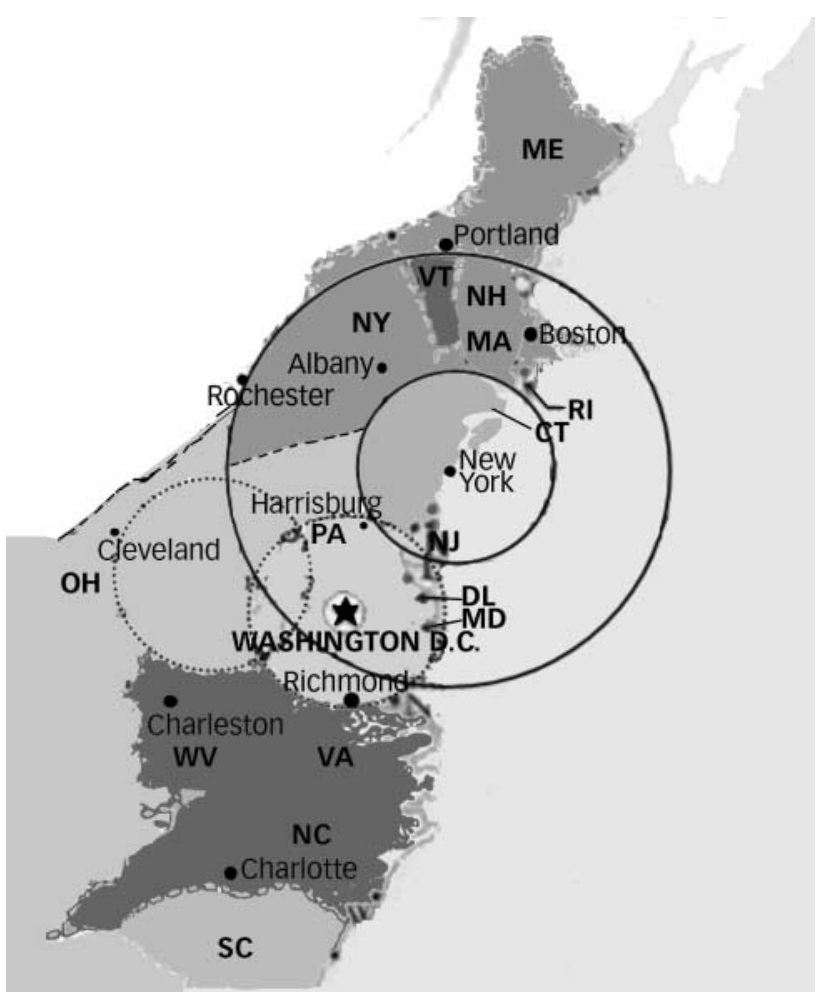

Fig. 1 Illustration of concentric distance circles used in analysis of impact of distance on suicide rates.

CT, Connecticut; DL, Delaware; MA, Massachusetts; MD, Maryland; ME, Maine; NC, North Carolina; NH, New Hampshire; NJ, New Jersey; NY, New York state; $\mathrm{OH}$, Ohio; PA, Pennsylvania; RI, Rhode Island, SC, South Carolina; VA, Virginia; VT, Vermont; WV, West Virginia.

surprisingly attenuated outside of directly affected areas. ${ }^{10}$ The relationship between geographic distance and suicide rates was therefore characterised in concentric circles (Fig. 1). All counties falling outside the immediate vicinity but within a 150-mile radius of an attack site were included in the first geographic tier around the sites. Counties at a distance of more than 150 miles and less than 300 miles from each site comprised the second tier. Counties in the first geographic tier falling within more than one attack site circle were eliminated from individual site analyses as were second tier counties falling within the first tier for any site. Because of the low daily count (not rate) of suicides around both the Flight 93 and Pentagon sites, we ultimately defined the 'immediate vicinity' of both sites to include all counties where any portion of the county fell within a 150-mile radius of the attack site.

\section{Controls}

Given the limitations inherent in observational studies, mortality rates could have fluctuated around 11 September 2001 for reasons not directly associated with the sociological influence of the attacks. Undetermined intent and ill-defined cause death rates were examined because incomplete investigation protocols for suicides often result in elevated numbers of 'hidden' suicides within these mortality categories. ${ }^{10-13}$ If local medical examiner's offices simply did not have the resources to investigate equivocal deaths with the usual degree of care after the attacks because of the increased mortality burden associated with the attacks, numbers of deaths in these categories might have increased significantly during this time period. Pancreatic cancer and Alzheimer's disease rates were also examined because these rates were believed to be relatively unaffected by news of the attacks. Finally, in order to identify seasonal or other recurrent spurious effects on rates of suicide, we examined rates for equivalent calendar days in the years 1998, 1999 and 2000. Pre-9/11 years, rather than post-9/11 years, were used as controls, because the anniversary effect so commonly seen after traumatic events might have influenced suicide rate levels in subsequent years.

\section{Analytic plan}

For all pre/post-9/11 comparisons, the day of 11 September 2001 was included in the pre-9/11 period. Pre- and post-9/11 mean suicide rates were computed as the mean of a negative binomial distribution because this method is appropriate for data based on counts and allows estimation of a parameter to adjust for overdispersion. A time series model of daily suicide rates was fit with SAS Proc ARIMA (SAS version 9.1.3) for Windows using only the pre-9/11 data so that a possible $9 / 11$ effect would not confound the model. The number of moving average and autoregressive components was determined by Akaike's information criteria (AIC) method. ${ }^{14}$ For consistency of presentation, time series analysis was used in all geographic areas even though for the New York City 150- to 300-mile concentric circle, District of Columbia 150-mile circle, and Somerset County 150-mile circle, the AIC method selected a model with no moving average or autoregressive components (i.e. white noise).

The pre-9/11 model was then applied to the pre- and post-9/11 periods combined, and step functions with the step at $9 / 11$ were added to the model to test for a possible increase or decrease in suicide rates due to the attacks-intervention analysis. ${ }^{15}$ The step functions are all zero when the $9 / 11$ effect is hypothesised not to be in operation and 1 when it is. To determine the length of time when rates were affected by $9 / 11$ events, models were fit with step functions corresponding to possible durations of the $9 / 11$ effect from 30 days up to 180 days in intervals of 30 days. Step functions are shown in Fig. 2. The step function that produced the best fit was identified by the AIC goodness-of-fit statistic. ${ }^{16}$ The same modelling and testing strategy was used for suicide rates in the control years $(1998,1999,2000)$ and for control condition death rates in 2001 (undetermined and ill-defined cause, pancreatic cancer and Alzheimer's disease). A $P$ of 0.01 was used as a cut-off for significance in all tests of effect in order to partially compensate for spurious significant results, given the number of analyses completed.

\section{Results}

\section{New York City area analysis}

Between 1990 and 2001, annual New York City primary metropolitan statistical area suicide rates trended slightly downwards, from a rate of $8.1 / 100000$ (1990) to 5.6/100000 (2001), with September suicide counts during those years averaging just over $8 \%$ (range 5.9-10.0) of all annual suicides. September 2001 suicides represented $6.98 \%$ of suicides for that year, ranking as the second lowest September percentage occurring during those years.

Figure 3 shows the 2001 New York City primary metropolitan statistical area daily rate of suicide for the 180 days before and after 11 September 2001. The mean daily rates for the complete pre- and post-attack periods were 0.017 and 0.014 suicides per 100000 people respectively. Using only the 181 day pre-9/11 data, the AIC method showed an ARMA $(0,6)$ model best fit the data. This model was refit, using all 361 days of data presented in Fig. 2. The best-fitting model was produced by the step function in which the effect lasted for 60 days after 9/11. Based on this model, the 


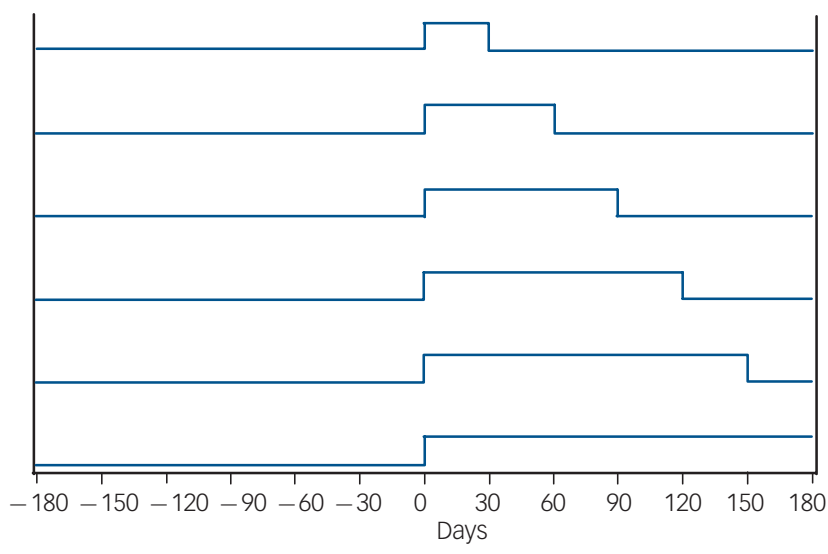

Fig. 2 Step functions indicating (from top down) 30, 60, 90, 120,150 , and 180 day durations of post-9/11 effect.

daily suicide rate was estimated to be 0.016 per day per 100000 people when the $9 / 11$ effect was absent, declining during this 60 -day post-9/11 period by an estimated average of -0.0039 per day per 100000 people (horizontal line in Fig. 3). This decline was significant $(t=2.9, P=0.0035)$.

Figure 4 shows the mean, post-attack daily suicide rate broken down into 30-day increments, illustrating the degree of fluctuation over time. This included a second drop in rates, between 151 and 180 days. As a result, the model in which the 9/11 effect lasted for the entire 180 days was also significant (post-9/11 change in daily suicide rate of -0.0028 per 100000 people, $t=2.4, P=0.0046$ ), whereas models for 90,120 and 150 days were not.

To determine whether post-9/11 declines in rates were similar to those found in years prior to 2001, the analysis for 2001 was repeated for each year from 1998 to 2000. No significant post-9/11 effect was found for any duration of time for any of these years. Although the mean change in 1998 over the post-9/ 11 180-day period was numerically larger than the corresponding mean change in $2001(-0.0034 v .-0.0028$ respectively), it was not significant at the 0.01 level. In total, these individual year analyses revealed a statistically significant post-9/11 drop in daily suicide rates only for the year 2001 (60 days: $t=2.9, P=0.0035$;

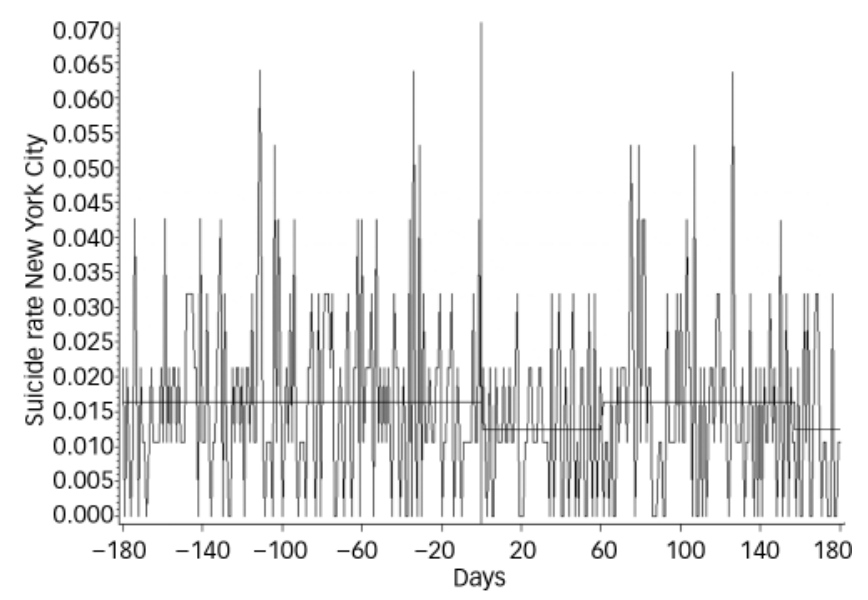

Fig. 3 New York City primary metropolitan statistical area daily suicide rates per 100000 people for 180 days before and after 2001, September 11 and time series estimates of mean suicide rates.
180 days: $\mathrm{t}=-2.8, P=0.0046)$, with differences estimated from the time series model being very close to differences in observed rates.

Finally, post-/pre-9/11 daily 2001 rate changes and significance levels for control conditions were as follows: undetermined cause of death (60 days: $+0.0030, P=0.5207 ; 180$ days: +0.00048 , $P=0.4076)$, ill-defined cause of death (60 days: +0.0021 , $P=0.2659,180$ days: $+0.0034, P=0.0132)$, Alzheimer's disease (60 days: $+0.00013, P=0.9318 ; 180$ days: $+0.00085, P=0.4535$ ), and pancreatic cancer deaths (60 days: $-0.00019, P=0.9442 ; 180$ days: $+0.0033, P=0.0975$ ). Thus, no post-9/11 rate was significantly different at the 0.01 level from the corresponding pre-9/11 rate for these conditions.

\section{New York City 150-mile and 300-mile concentric circle analyses}

Mean suicide rates for pre-/post-attack time periods are also given in Fig. 4 for the counties falling outside the New York City primary metropolitan statistical areas but within a 150 -mile radius of the World Trade Center. The pattern of decreasing and increasing rates over the 180 -day post-9/11 period is generally parallel to that found within New York City. Time series modelling showed an ARMA $(15,0)$ model resulted in the best fit of the pre-9/11 data. This model detected a statistically significant 180-day post-9/11 estimated drop in suicide rates $(-0.0044$, $t=-2.6, P=0.0096)$ for counties within 150 miles of the attacks - a difference that was again found to be very close to the observed rate difference of -0.00447 . Like the model for New York City, the 60-day model trended downwards, but failed to reach significance at a distance of 150 miles from the city. Neither control year analyses nor other 2001 mortality categories revealed significant post-9/11 rate changes, except that significant increases in ill-defined cause daily death rates were observed for the 180-day $(+0.0052, \quad t=3.4, \quad P=0.0008), \quad 150$-day $(P=0.0002), \quad 120$-day $(P=0.0054)$, and 90 -day $(P=0.0048)$ post-9/11 periods. This pattern was also observed during control years and was therefore interpreted as unrelated to the $9 / 11$ attacks.

The concentric circle extending from 150 to 300 miles away from Ground Zero demonstrated no significant difference in suicide rates for any post-9/11 time period studied.

\section{Pentagon area and Somerset County}

The Washington DC primary metropolitan statistical areas includes counties and portions of counties within the District of Columbia, Virginia, West Virginia and Maryland. Suicide rates within this area are generally somewhat higher than those found in the New York City primary metropolitan statistical areas, although raw suicide counts are about half the number found there. Between 1990 and 2001, annual rates of suicide in the District of Columbia ranged from a low of 6.6/100 000 (1991) to a high of 9.44/100000 (1994), without a clear trend over time (12-year average: 7.95/100 000). The suicide rate for 2001 was $7.44 / 100000$, which was somewhat higher than the annual rate for the previous 2 years. On average, September suicides comprised $8.44 \%$ of annual District of Columbia suicides, whereas the number of suicides occurring during September 2001 represented $8.0 \%$ of all suicides for that year.

Compared with pre-9/11 rates, no significant difference in post-9/11 suicide rates was discernible for the Washington DC primary metropolitan statistical areas or for the 150-mile circle around the Pentagon. Although mean daily suicide rates dipped slightly for the first 30 days after $9 / 11$ in both areas (Fig. 3), they then rose above pre-9/11 levels for the subsequent 2 months (e.g. post-9/11 days 31-90). The same pattern was noted for the 150-mile 


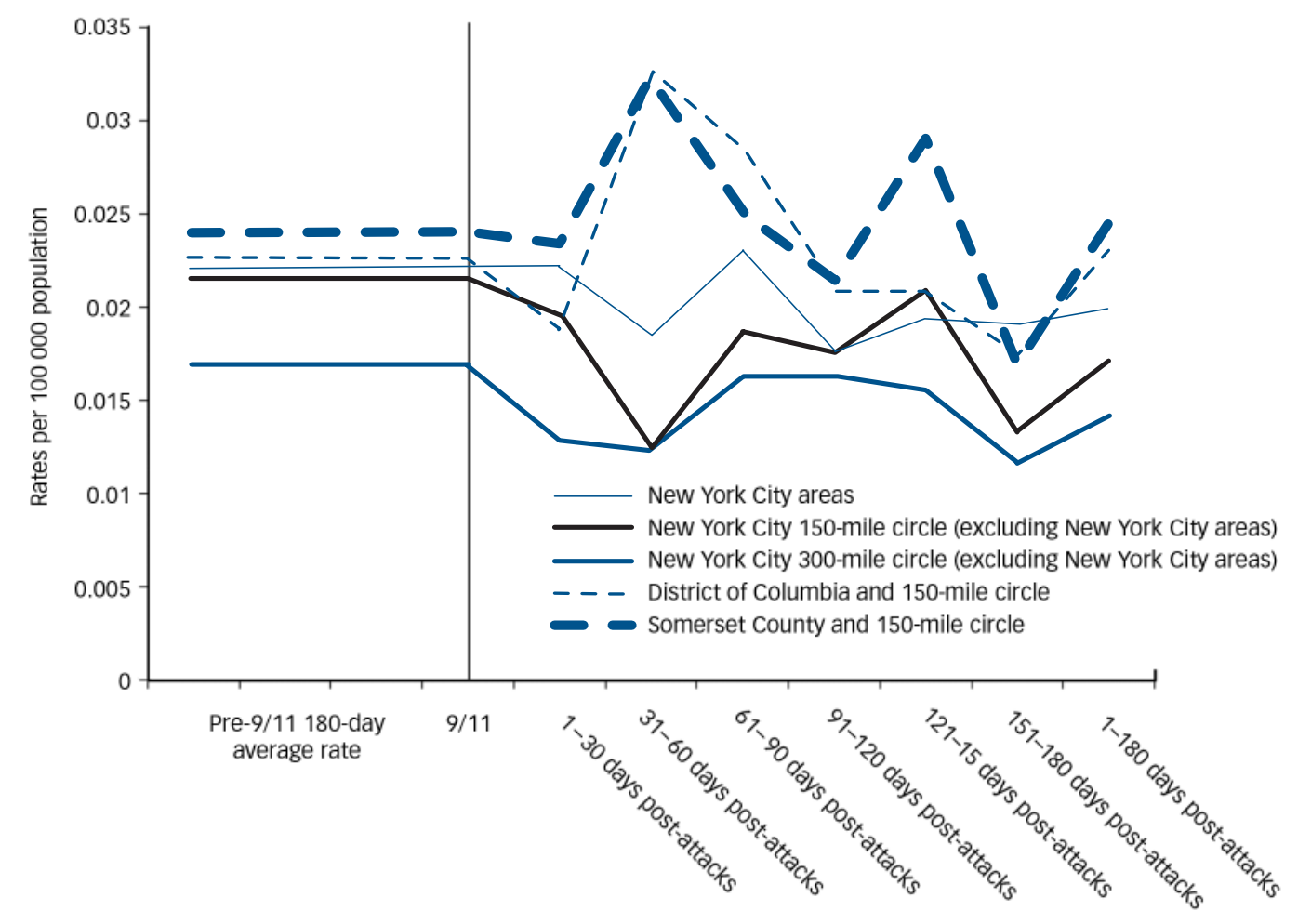

Fig. 4 Suicide rates per 100000 people for 2001 by time interval and geographic region.

circle around Somerset County. As a result, no pre-/post-9/11 rate differences achieved significance and no control year or control conditions were analysed.

Finally, there were also no significant post-9/11 rate trends in the area within 150 miles of the Flight 93 crash site. The suicide rate fluctuated above pre-9/11 rates on a monthly basis, but - like the 150-mile circle around the Pentagon - the post-9/11 180-day rate average around the Flight 93 crash site remained essentially unchanged from the equivalent pre-9/11 rate.

\section{Discussion}

This study examined trends in daily US suicide rates around the crash sites after the 11 September 2001 terrorist attacks and found that although the attacks did not significantly influence national rates, the rates for individuals whose place of residence was within 150 miles of the World Trade Center were reduced. The effect was most prominent during the first 2 months after the attacks, but influenced average daily rates across a 180-day time period as well. The effect was observable in an area extending 150 miles outwards from Ground Zero, and the lack of post-9/11 rate change for other cause-specific mortality conditions within this geographic area suggests that the effect was not related to overburdened death investigation and registration systems. The absence of a corresponding effect in years preceding 2001 suggests that the effect was also not because of seasonal rate fluctuations. The notable absence of any such effect in the area surrounding both the Pentagon and the Flight 93 crash sites contrasts sharply with the World Trade Center pattern.

\section{New York City and European response patterns}

The decline in New York City suicide rates is perhaps not surprising, given the profound impact of the event and its sequelae on the daily lives of those who lived within the city. Countless news reports from that time period document the increased social cohesion among New York City residents, which included high levels of support for Ground Zero clean-up workers and uniformed civil servants. ${ }^{17,18}$ This sociological response pattern supports the Durkheimian position that increased group cohesion in post-attack Manhattan and surrounding areas directly precipitated the declining suicide rates.

Two alternative explanations seem less likely. The first is that increased access to mental health treatment available in the city via free, walk-in Project Liberty mental health clinics during the months after the attacks mediated the drop in suicide rates. ${ }^{19-21}$ The second possibility is that, perhaps because of the media attention, a temporary increase in tolerance for mental health help-seeking may have occurred over the months following the attacks independent of any increase in group cohesion, producing an environment more supportive of treatment-seeking than usual. Although either possibility may have contributed to the maintenance of lower suicide rates over the latter part of the 180 -day study time period, it is not likely that either would have precipitated a significant drop in rates beginning immediately after the attacks. Instead, it seems more likely that suicide rates dropped on the morning of 12 September in direct response to the event itself.

In the weeks and months following 9/11, the World Trade Center attack was widely understood to be an attack on the financial structure of first-world economies. ${ }^{22}$ As two of the most powerful economic centres in the world, ${ }^{23}$ it is therefore perhaps not so surprising that popular reaction and suicide rate performance in New York City and Great Britain mirrored each other. Within hours of the attacks British Prime Minister Tony Blair declared that Britain stood 'shoulder to shoulder' with America against the 'new evil of mass terrorism. ${ }^{24}$ As a population well acquainted with acts of terrorism, British people seem to have responded in-kind during those initial post-attack days. 
The Dutch experience, however, may have been quite different. Multiple sources since the attacks have suggested that $9 / 11$ was experienced as a divisive (rather than a unifying) social influence in The Netherlands. ${ }^{25,26}$ In short, a singular, global event seems to have increased social cohesion in some societies, and to have contributed to fragmentation of the social fabric in at least one other.

\section{Negative Washington DC effect}

In contrast to New York City and Great Britain, 9/11 apparently did not have a significant influence on suicidal behaviour among individuals whose place of residence fell within the District of Columbia primary metropolitan statistical area, or within a 150-mile radius of the Pentagon. Other, post-attack populationbased surveillance reported normative rates of post-traumatic stress disorder among Washington DC residents and higher rates in more geographically distant cities, lending indirect corroboration to this study's findings in this area. ${ }^{10}$ Why would the events of 9/11 have had less impact on residents of the US capital than on residents of New York City? Differences in the shared experience of the World Trade Center and Pentagon attacks afford one level of explanation. The relative scope of the two attacks in terms of death toll, impact on everyday life and news coverage all contributed to an early designation of the World Trade Center site, and not the Pentagon, as the symbolic 'Ground Zero.' ${ }^{10}$ In addition, the 2001 anthrax attacks, which began on 18 September 2001, may have diverted attention within Washington DC, as the final two letters were mailed to members of the US Senate. It should be noted that Durkheim ${ }^{2}$ also identified nineteenth century political events with a seeming lack of effect and assumed that the absence of an increase in collective loyalty to a 'common cause' after these events was the primary reason for negligible rate change.

\section{Relationship prior to $9 / 11$ studies}

This study's positive findings stand in contrast to negative findings from two other very recently published studies of post-9/11 New York City suicide rates. ${ }^{27,28}$ As in this study, a drop in suicides after $9 / 11$ was noted in both reports, but the finding was not regarded as significant in either. There are important methodological differences across studies. In particular, although both studies utilised a single, monthly data point (i.e. a monthly count or rate of suicide) and examined longer post-attack time periods, the present study adopted an increasingly common approach in this line of investigation, involving time series analysis of daily rates. ${ }^{29,30}$ Given that demonstrations of post-crises suicide rate fluctuations have uniformly been both nuanced and transitory, ${ }^{30}$ this more granular method may be necessary and characterise the phenomenon.

\section{Limitations}

Several methodological limitations must be kept in mind in relation to this study's findings. Our study locates fatalities by residence of the deceased rather than by place of death, under the assumption that the deceased's cultural ties are better described by place of residence, and this may influence findings in places such as the Washington DC area with its highly transitory population subgroups. Second, although daily rates of suicide demonstrated relative consistency across years for a variety of mortality conditions, suicide is a rare event and the relatively small numbers of suicides near some attack sites may have erroneously contributed to negative findings (type II error). In particular, the rural nature of the Somerset crash site was associated with exceedingly low suicide base rates, reducing both the potential for a collective, shared 9/11 experience and the capacity of our statistical approach to detect an effect. Finally, this is a correlational study and the possibility therefore remains that New York City effects were caused by some force other than the events surrounding $9 / 11$.

\section{General factors contributing to effects}

In the USA, the local World Trade Center effect spread outwards to encompass an area with an approximate 300-mile diameter (150-mile radius). England at its widest and longest is approximately 300 miles by 460 miles. It is possible that the nature or intensity of shared cultural response needed to affect factors such as suicide rates may exist only within geographic areas of a limited size and substantial population density. Regardless, the contrasting nature of response across the New York City and Washington DC primary metropolitan statistical areas, Great Britain and The Netherlands suggest that event proximity may be less important than other response characteristics. Based on the $9 / 11$ experience, contextual factors that may potentially contribute to differential group response and suicide rate fluctuation include: immediacy and intensity of shared threat experience, leadership response, presence/absence of other threats or serious concerns, and nature of local media coverage.

Over the past six decades, the annual US suicide rate has varied by less than five people per 100000 - a time period in the USA encompassing four wars, seven recessions and unprecedented advancement in the diagnosis and treatment of mental illness. Considering the relatively intractable nature of the rate during this time period a finding of even temporary fluctuations within specific locations is noteworthy. Given that both temporal and geographical aspects of suicide rates after significant social events appear to be measurable, further research of this kind may produce valuable insights into to how these rates are mediated by sociological forces and which suicidal groups are most affected.

Cynthia A. Claassen, PhD, Clinical Research Core, VISN 2 Center of Excellence for Suicide Prevention, and Associate Professor, Department of Psychiatry, University of Rochester, New York; Thomas Carmody, PhD, Department of Clinical Sciences, University of Texas Southwestern Medical Center, Dallas; Sunita M. Stewart, PhD, Department of Psychiatry, University of Texas Southwestern Medical Center, Dallas; Robert M. Bossarte, PhD, Epidemiogy and POpulation Studies Core, VISN 2 Cent of Excer Mossarte, PhD, Epidemilogy and Population studies Core, VISN 2 Center of Excellence for Suicide Prevention, and Assistant Professor, Department of Psychiatry, University of Rochester, New York; Gregory L. Larkin, MD, MSPH, FACEP, Department of Surgery (Emergency Medicine), Yale University, New Haven, Connecticut; Wayne A. Woodward, PhD, Department of Statistical Science, Southern Methodist University, Dallas, Texas; Madhukar H. Trivedi, MD, Department of Psychiatry, University of Texas Southwestern Medical Center, Dallas, USA

Correspondence: Cynthia A. Claassen, PhD, c/o Center of Excellence, Canandaigua VAMC, 400 Fort Hill Drive, Canandaigua, NY 14424, USA. Email: Cindy.Claassen@va.gov

First received 12 Aug 2009, final revision 21 Dec 2009, accepted 11 Jan 2010

\section{Funding}

C.A.C.'s work is partially supported by a grant from the American Foundation for Suicide Prevention (AFSP) and the Timberlawn Foundation. R.M.B. and G.L.L.'s work was likewise partially supported by AFSP.

\section{Acknowledgement}

The authors thank Chris Rogers, PhD, of the Research Data Center at the National Center for Health Statistics, Hyattsville, Maryland, for his support during these analyses.

\section{References}

1 Salib E. Effect of 11 September 2001 on suicide and homicide in England and Wales. Br J Psychiatry 2003; 183: 207-12. 
2 Durkheim E. Suicide: A Study in Sociology. Free Press, 1951 [1897].

3 De Lange A, Neeleman J. The effect of the September 11 terrorist attacks on suicide and deliberate self-harm: a time trend study. Suicide Life Threat Behav 2004; 34: 439-47.

4 Starkman M. The terrorist attacks of September 11, 2001, as psychological toxin. J Nerv Ment Dis 2006; 19: 547-50.

5 Injury International Collaborative Effort (ICE). ICD Framework: External Cause of Injury Mortality Matrix. ICE, 2009 (http://www.cdc.gov/nchs/injury/ice/ matrix10.htm)

6 Division of Vital Statistics. Multiple Cause Mortality: List of 113 Selected Causes of Death. Centers for Disease Control and Prevention, 1999.

7 World Health Organization. The ICD-10 Classification of Mental and Behavioural Disorders: Clinical Descriptions and Diagnostic Guidelines. WHO, 1992.

8 Jougla E, Pequignot F, Chappert J, Rossollin F, Le Toullec A, Pavillon G. Quality of suicide mortality data [in Italian]. Rev Epidemiol Sante Publique 2002; 50: 49-62.

9 Arias $\mathrm{E}$, Anderson R, Kung H, Murphy S, Kochanek K. Deaths: final data for 2001. Natl Vital Stat Rep 2003; 52: 1-116.

10 Schlenger W, Caddell JM, Ebert L, Jordan K, Rourke KM, Wilson D, et al. Psychological reactions to terrorist attacks: findings from the National Study of American's Reactions to September 11. JAMA 2002; 288: 581-8.

11 Andriessen $\mathrm{K}$. Do we need to be cautious in evaluating suicide statistics? Eur J Public Health 2006; 16: 445

12 Phillips DR, Ruth TE. Adequacy of official suicide statistics for scientific research and public policy. Suicide Life Threat Behav 1993; 23: 307-19.

13 Mohler B, Earls F. Trends in adolescent suicide: misclassification bias. Am J Public Health 2001; 91: 150-3.

14 Box GEP, Jenkins GM, Reinsel GC. Time Series Analysis: Forecasting and Control (4th edn). Prentice Hall, 2008.

15 Box GT, Tiao GC. Intervention analysis with applications to economic and environmental problems. J Am Stat Assoc 1975; 70: 70-9.

16 Akaike $\mathrm{H}$. A new look at the statistical model identification. IEEE Transaction on Automatic Control 1974; AC-19: 716-23.

17 Public Broadcasting System (PBS). Heroes of Ground Zero. PBS, 2002 (http://www.pbs.org/wnet/heroes/).
18 Time Magazine. Person of the Week: The Worker at Ground Zero. Time Magazine, 2002 (http://www.time.com/time/nation/article/ $0,8599,254288,00 \cdot \mathrm{html})$.

19 Covell N, Donahue S, Allen G, Foster J, Felton C, Essock S. Use of Project Liberty counseling services over time by individuals in various risk categories. Psychiatr Serv 2006; 57: 1268-70.

20 Donahue S, Jackson C, Shear K, Felton C, Essock S. Outcomes of enhanced counseling services provided to adults through Project Liberty. Psychiatr Serv 2006; 57: 1298-303.

21 Felton C. Project Liberty: a public health response to New Yorkers' mental health needs arising from the World Trade Center terrorist attacks. J Urban Health 2002; 79: 429-33.

22 Chernick H. Resilient City: The Economic Impact of 9.11. Russell Sage Foundation, 2009

23 Scott A. Global City-Regions: Trends, Theory, Policy. Oxford University Press, 2001.

24 White $\mathrm{M}$, Wintour P. Blair calls for world fight against terror. The Guardian 2001; 12 September (http://www.guardian.co.uk/politics/2001/sep/12/ uk.september11).

25 Wilson S. Dutch Imams 'Leaving In Droves'. BBC News Europe, 2007 (http://news.bbc.co.uk/2/low/europe/6279785.stm).

26 Buijs, FJ. Muslims in the Netherlands: Social and political developments after 9/11. J Ethn Migr Stud 2009; 35: 421-38.

27 Mezuk B, Larkin GL, Prescott MR, Tracy M, Vlahov D, Tardiff K, et al. The influence of a major disaster on suicide risk in the population. $J$ Trauma Stress 2009; 22: 481-8.

28 Pridemore WA, Trahan A, Chamlin MB. No evidence of suicide increase following terrorist attacks in the United States: an interrupted time-series analysis of September 11 and Oklahoma City. Suicide Life Threat Behav 2009; 39: $659-70$.

29 Salib E, Cortina-Borja M. Effect of 7 July 2005 terrorist attacks in London on suicide in England and Wales. Br J Psychiatry 2009; 194: 80-5.

30 Detsky ME, Sivilotti ML, Kopp A, Austin PC, Juurlink DN. Deliberate selfpoisoning in Ontario following the terrorist attacks of September 11, 2001 JAMA 2005; 294: 1900-1. 